\title{
Non-Animal Models for Research and Toxicity Testing of Drugs
}

\author{
Abhishek Ajmera, Parshuram Shendge* \\ Department of Pharmacology, School of Pharmacy and Technology Management SVKM's NMIMS, Shirpur Campus, \\ Dhule, Maharashtra, INDIA.
}

\begin{abstract}
All drug discovery methods, right from 'trial-and-error' approach to modern rational synthesis of drugs, make use of animals to check for efficacy and toxicity of compounds. This results in millions of animals being sacrificed every year. Following a global debate on "cruelty of animals", various acts were made and enforced in order to protect animal rights. As a work, around to these animal protection acts, drug discovery scientists started finding alternative approaches to animal studies for research. This review attempts to compile some of the more important non-animal models which are being used for testing safety and efficacy of drugs in preclinical stages.
\end{abstract}

Key words: Refinement, Reduction, Zebra fish, Tissue culture, Caenorhabditis elegans, Saccharomyces cerevisiae, Leukotriene Inhibitory Factor.

\section{INTRODUCTION}

Advances in technology has led man to shift the focus of discovering new drugs for satisfying his medical needs from natural resources to semi-synthetic and synthetic approaches. ${ }^{1}$

Whatever the approach, animals are being indiscriminately used for testing the purity, safety and efficacy of compounds. ${ }^{2}$ As research and development in drug discovery increases, the number of animals used for testing also increases. Each year around 2-3 million animals such as rabbits, mice, hamsters, birds, guinea pigs etc. are being used for experimental research.

The pain, stress, trauma and even death of experience by these animals have become a globally debate issue. Argument is that being alive, animals have right against pain and therefore their experimental use is wrong and need to stop. In order to implement, various acts and laws have been passed. One such is in 1824, organization for animal rights was formed by Royal Society for Prevention of Cruelty to Animals. They passed an act in 1876 against cruelty to animals. This act came into force in 1960 ,
1963 and 1966 in India, France, and USA. Various organizations such as International Conference for Harmonization (ICH), National Institute of Health (NIH) govern and regulate this Act. $^{3}$

In order to bypass the constraints imposed by the various acts and laws, researchers started developing non-animal methodologies. There are range of non-animal techniques available for biomedical and pharmacological research and toxic study. Non-animal models are based upon the principle of studying physio-chemical nature of drug outside the body, which is then induced drug into animals. This leads to minimal use of animals and also helps to save animal life. In this article, we have discussed some of non-animal techniques in-vitro assays, organs-on-chips, using lower phylogenic animals, using micro-organisms, etc. ${ }^{4}$

\section{LIMITATIONS OF ANIMAL TESTING}

\section{Scientific limitations}

Scientific limitations are based on the facts that there are differences among the gender
Submission Date: 14-04-2017; Revision Date: 08-05-2017; Accepted Date: 25-09-2017

DOI: 10.5530/ijper.51.4s.80 Correspondence: Parshuram Shendge, Department of Pharmacology, School of Pharmacy and Technology Management SVKM's NMIMS, Shirpur Campus, Dhule, Maharashtra 425405, INDIA.

Phone no: +91-9769525957;

E-mail: shendge.

parshuram@gmail.com

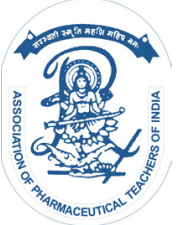

www.ijper.org 
and species. This difference creates deviations in the results of pharmacokinetics, pharmacodynamics and toxicological studies. One demonstrative example is the P450 dependent mono-oxygenase of the xenobiotic family of enzymes. Their major function is to oxidize foreign substances such as drugs, toxins and generate toxin-free blood-soluble compounds which makes kidney function easier. Species differences cause deviations or differences in rates of metabolic pathways and decrease efficacy. This is the key failure of animal testing. Thus only $8 \%$ drugs tested in animals have equivalent results in humans. Another example of 100\% failure of animal trials is testing of HIV medications. Till date, anti-HIV drugs are tested on chimpanzees which inherently have different metabolism than humans. ${ }^{5}$

\section{Regulatory limitations}

Massive animal killings increased the social concern into minds of public and also governing authorities. Such authorities prohibit laboratory animal use when nonanimal alternative models are available. Further, authorities also demand justification about the use of animal models. One such governing act in USA is Animal Welfare Act, 1966. Under this act, mice, birds, rats receive protection. In addition, studies should be carried out after applying analgesics or anesthetics and researchers should not repeat previous experiments unnecessarily. In 2005, Japanese Animal Protection Law was enforced and in 2006 it focuses on alternatives models. This law was enforced because only Japan in 2004 consumed 1.1crore living vertebrates either for toxicity test, educational use or for biomedical research. Japan Law strictly states that animal use must be under supervision of Animal Ethical Committee. $^{3}$

\section{Concept of 4R}

To overcome the draw backs of animal model and avoid the unethical procedures associated with animal testing, the concept of $4 \mathrm{R}$ is used. Charles Hume and William Russell at Universities Federation of Animal Welfare introduced the concept of " $3 \mathbf{R}$ " to the world. ${ }^{6}$ It includes reduction, refinement, replacement and responsibility. This concept is applied to use of laboratory animals for testing of drug. In order to implement this strategy, various methods, models and substitute animals were used. The $4^{\text {th }} \mathrm{R}$ i.e. responsibility is introduced in recent years. ${ }^{8}$ These 4R's are as follows:

\section{Reduction}

This strategy aims to decrease the use of laboratory or experimental animals. The use of statistical data and careful selection of study design can produce effective scientific results. For early stage compound screening, in-vitro cell culture is available. In order to study drug metabolism and elimination, human hepatocyte cultures are used. ${ }^{9}$ For differentiating toxic compounds from non-toxic towards, embryo in-vitro embryonic stem cell culture test are used. ${ }^{10}$

\section{Refinement}

Just like humans do not liked being caged, animals also do not like to be caged. Caging the animals causes stress to animals. It causes fear, anxiety among the animals. Pain, distress, discomfort causes fluctuations in the animal hormone levels which directly or indirectly produces errors in the results. Hence, number of animals required also increases. So, refinement is important to improve the animal housing facilities and quality of research. ${ }^{11}$

\section{Replacement}

Animal replacement is, "any scientific method employing non-sentient material which may replace use of conscious living vertebrates in animal experimentation". Replacement is achieved by use of non-living system and computer simulation. Different alternatives are used such as cultures, in-vitro techniques, computer models, etc. ${ }^{11,12}$

\section{Responsibility}

The recent addition of $4^{\text {th }} \mathrm{R}$ is "RESPONSIBILITY". This $\mathrm{R}$ indicates the safety and prevention from cruelty to animals is the prime responsibility belonging to humans. This has led to growth of new era which is based on performance outcomes. This " $\mathrm{R}$ " indicates that animal life is precious for biomedical advancement. ${ }^{8}$

\section{Alternate Methods to Replace Animal in Drug Testing}

Different methods have been developed to replace animals during drug testing in research and toxicology study. We are discussing few of them which will be useful (Figure 1).

\section{In Silico Method}

Drug discovery requires a huge capital and investment. For discovery, various protocols must be obeyed. One such protocol is regarding Animal Testing and Safety. In order to reduce the workload, one can replace animal testing with in-silico model's methods. In silico models are based on basic principles of biology. Specially designed computer models and computer software help to design new drugs. It predicts possible binding sites of drugs and their receptors, thus reducing or decreasing the number of animals used. This is possible by use of software- Computer Aided Drug Discovery (CADD) which predicts the probable therapeutic and pharmacological action of drug and its possibility to bind receptors. 


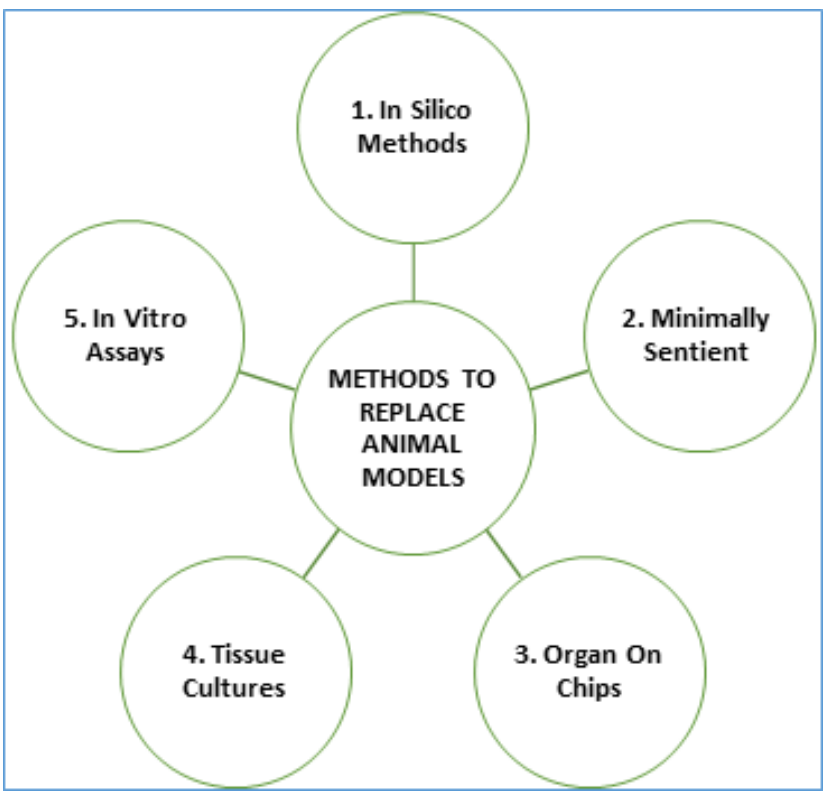

Figure 1: List of methods to replace animals in drug testing

CADD helps to construct new drug for the specific receptor binding site. This will avoid use of chemicals which does not have any biological activity. Hence the total number of animals required are lowered which help us to attain objective of $4 \mathrm{R}$ strategy. ${ }^{13}$

Another method which is in practice is Quantitative Structure Activity Relationship (QSAR). It is theoretical method which predicts the therapeutic action of the compound on the basis of chemical groups present on the parent compound. QSAR is a mathematical expression of relationship between physicochemical and biological properties of drug. QSAR quickly predicts carcinogenicity and mutagenicity of drug candidate. These computer models are more accurate, inexpensive and give us quick results. $^{14}$

\section{Minimally Sentient}

For the development of drug or medicine, it has to comply with several regulatory authorities. One such authority includes Animal Safety and Regulatory Authorities. As per Authority guidelines, it allows minimum use of live vertebrate's animals. Besides, Animal Ethical Committee have several prohibitions on testing higher animals such as guinea pigs, monkeys, etc. Therefore, there arises need for the use of lower-phylogenetic orders of animals as a substitute for higher animal. In 2007, Cosson et. al. suggested that for assays of bacterial infection, one can choose protozoan over rodents for study. The reason is bacterium Pseudomonas aeruginosa follows same mechanism for protection in unicellular amoeba and in multicellular mammalian cell. This opens the way to use lower vertebrates and invertebrates for testing of drugs in pre-clinical trials. ${ }^{15}$

\section{Lower vertebrates}

They are mainly used because of similarity in genetic composition with vertebrates. Also, less ethical guidelines need to be followed. The most easily available is Danio rerio commonly known as zebra fish found in freshwater with length $2-4 \mathrm{~cm}$ (Figure 2). Zebra fish have transparent body helps in observing its internal organs. This transparency allows easy screening, direct observation of development stages, toxicity studying and many more. Starting from infancy to adulthood, Danio reria have been used for various applications. It's short life cycle, small size and high fecundity makes zebra fish fit for laboratory use. ${ }^{16}$ Zebra fish requires small space, low maintenance and low man-power. The embryos and larvae can be easily developed and used for testing purposes in petri-dishes. ${ }^{17}$ For molecular and genetic study, zebra fish is best choice as whole genome sequence is easily available. Currently zebra fish is used in cancer research, neurological malfunctions, mutation of organ cells due to chemicals study, behavior study and lot more. ${ }^{17}$

\section{Invertebrates}

Similarly, to lower vertebrate animals, invertebrates also have wide range of laboratory uses in the research of different diseases such as Parkinson's disease, cell aging, diabetes. The benefit of using invertebrates are brief life cycle, short size, maintenance and housing cost are less. The only disadvantage is that they do not have adaptive immune system which causes some dis-similarities in human diseases. ${ }^{18}$

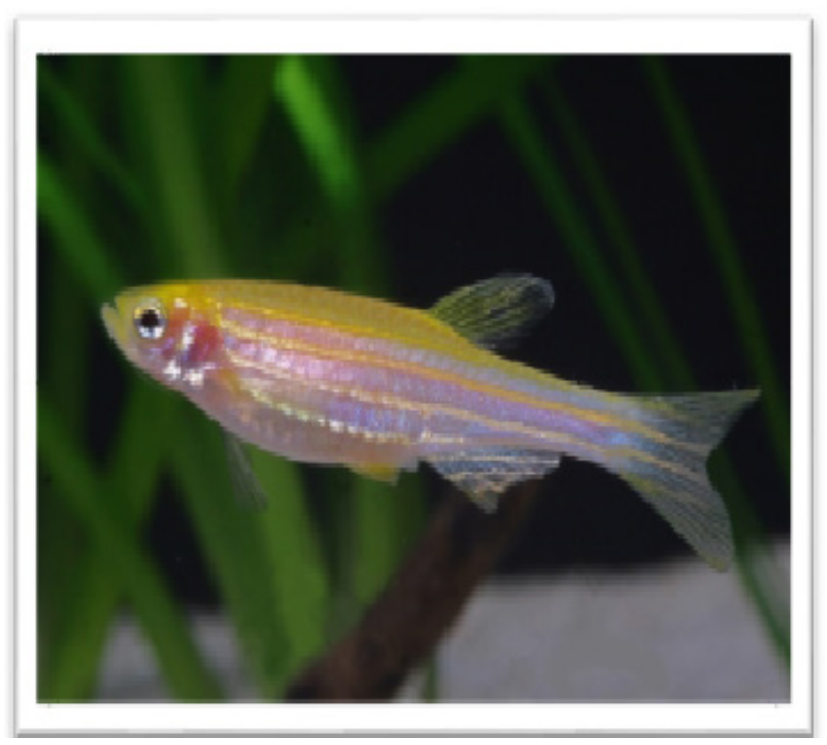

Figure 2: Zebra fish 


\section{Drosophilia melanogaster}

These invertebrates are widely used. Fruit fly has well-studied genome which helps in study of molecular mechanisms for human diseases. $75 \%$ of genes have homologous functions with human gene (Figure 3). Due to short life cycle, rapidly results are produced by fruit fly. The stages of life cycle are-embryo stage, larva stage, pupa stage and adult stage. Each stage is used for research and hence fruit fly is considered as multiple model organism. ${ }^{18,19}$ Embryo stage is used for organogenesis study, cell fate determination study, axon path finding study. Larva is used for physiological and growth processes such as foraging. Adult stage is very complex stage like humans. Hence, useful for various structural studies such as heart, gut, kidney, lungs. ${ }^{19}$ The unique feature of fruit fly is that it shows similar action to central nervous system drugs with mammals. The brain is extraordinary because it has more than 1,00,000 neurons forming network which controls various complicated behaviors like sleep, feeding, learning, flight navigation. Thus, fruit fly is used for human genetics and diseases such as Alzheimer's disease, Parkinson's disease, and Huntington disease..$^{20,21}$

\section{Caenorhabditis elegans}

Caenorbabditis elegans belongs to eukaryotic nematode. This minute multicellular organism is $1 \mathrm{~mm}$ in size and have short life span (around 2 to 3 weeks). Like zebrafish it is transparent, has simple cellular structure. Life cycle contains various stages like embryogenesis, morphogenesis and final adult stage. It is used to study various diseases like Parkinson's disease, Alzheimer disease, cancer anddiabetes. ${ }^{22-25}$

\section{Microorganism}

\section{Saccharomyces cerevisiae}

Saccharomyces cerevisiae commonly known as brewing yeast. Due to rapid growth, well defined genetic system

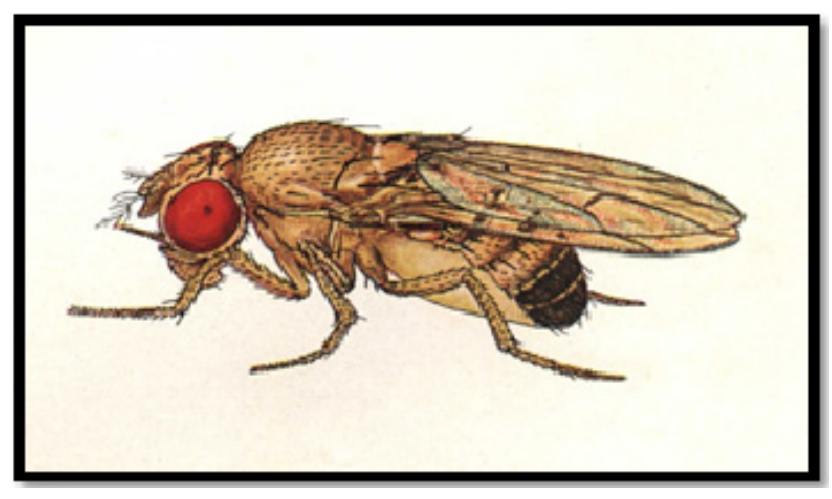

Figure 3: Drosophilia melanogaster and highly versatile DNA transformation system, it is most popular and important model. They can be grown on solid as well as liquid culture media. Due to short generation time, it is easy to grow and analyze large population on cultural media. ${ }^{26}$ Saccharomyces cerevisiae contains about 16 chromosomes with 13 million base pairs with extra nuclear genome in mitochondria. The number and size of the genes are relatively small. Saccharomyces cerevisiae shows multicellular organism like similarity in cellular structure as well as in life cycle makes it best candidate for drug testing. Many cells bound organelles of Saccharomyces cerevisiae mimic the functions of mammalian cells, therefore it is used to understand apoptosis, its regulation which is useful in cancer research. ${ }^{27}$ Saccharomyces cerevisiae is useful in understanding cellular progression of different diseases like Alzheimer's, Parkinson's and Huntington's diseases. ${ }^{28,29}$

\section{Organ-On-Chips}

Human organs are complex in their specialized structure, cells, tissue and carries one or more unique functions. Because of such complex nature, there are no such reliable models that have ability to demonstrate the exact or nearby accurate functions. Scientist as well as researchers are left with two options either carry in-vitro testing of human cells or perform in-vivo testing in animals. Both options have their own drawbacks. ${ }^{30}$ To study human cell, it is tough task to obtain exact human cell from the homogenous population due to constant variation among them. Even if these cells are obtained then problem arises, that they are quite sensitive to passaging, altered phenotype and due to variation, changing metabolic activities. Another problem faced by researchers is that for organ cultures and use, advanced technologies are required. To overcome these problems, the use of immortalized cells are preferred. But for immortalization, certain cellular activities needed to be disturbed that have been not yet studied deeply the deviations or differences from the initial or primary cell behavior. ${ }^{31}$ To cross all these barriers, "microfluidic techniques" have been emerged. In the recent decades, major changes have been taken in the field of microfluidics focusing on "organ on chips". The word microfluidics is the combination of two words "micro" meaning small and "fluidics" referring to set of movements of liquids of gas. Thus, the combination of tissue engineering and micro-engineering allows the impact to grow environment on both, human cell cultures as well as animal models supporting the growth of human cells in physiological relevant conditions (Figure 4). ${ }^{32}$ 


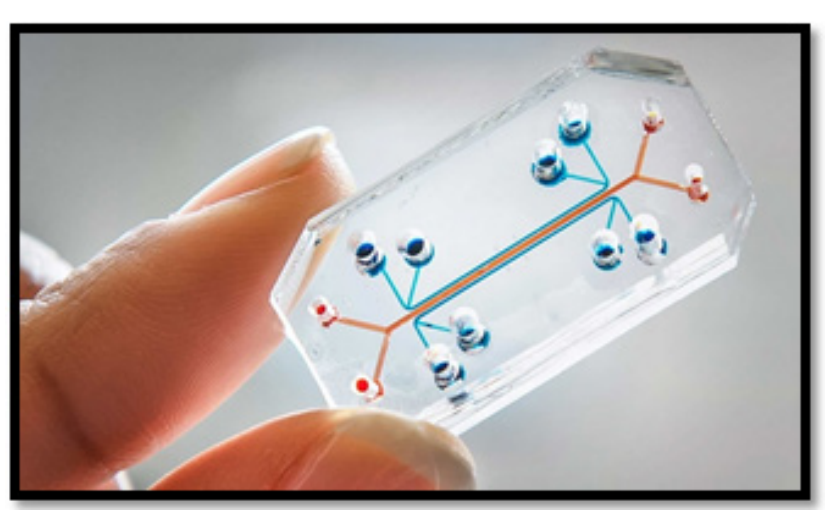

Figure 4: Organ-on-Chip

\section{Skin-on-chips}

The skin is often called "largest organ" which functions as protective barrier between human body and surrounding environment. Therefore, the study of physiology of skin and its layers is mandatory for the application of safe topical products such as creams, lotions, powder, cosmetics. In-vitro static study demonstrates only the upper most layer i.e. epidermis which is easily accessible, but the deeper layers of skin are not easily accessible. ${ }^{33}$ Organ-on-chip model is helpful for deep study of skin. Full thickness skin model was created for in-vitro purpose by inoculating human fibrinoblast cultures in collagen type-I medium matrix. This lead to the growth and development of dermis layer. Once the dermis layer is grown fully, for obtaining hair follicles, it is seeded with melanocytes and keratinocytes. The full growth development represents Human Skin Equivalent (HSE). The newly developed model shows 3-4 layers of keratinized cells and a clear difference between dermis and epidermis layer. ${ }^{34}$

Recent development shows that it is possible to investigate the effects of shear stress on growth of skin. The newly advanced chip model design includes two fluidic chambers. First chamber includes skin biopsies grown over ex-vivo subcutaneous tissue such as adipose cells, macrophages in liquid-air interface chamber. Second chamber consists of submerged follicular hair extracts. The results of merging of subcutaneous tissue was huge success in chip device which in case of static cultures, these layers were shattered off. ${ }^{35}$ An attempt was made by Wagner et al. for demonstrating organ cross talk such as skin and liver. He designed the same chamber but with slight modifications. The first chamber remained same but second chamber consists of hepatocytes (liver cells). The experiment showed that hepatocytes produce albumin which is consumed by skin. But the differentiating characteristic is on reaching equilibrium state liver did not produce excess albumin. This shows organ talk between skin and liver which might in future opens the door for "fully body-on-a-chip device". ${ }^{36}$

\section{Lungs-on-chip}

The major function of pulmonary system is gas-exchange between air and blood. Thus, mimicking the pulmonary system in-vitro was a challenging task. At alveoli gases exchanged in lungs. The alveolar epithelium cells are subjected to variety of chemical and mechanical stimuli because of infections, inhaled particles and complications from various diseases. ${ }^{37}$ Researchers and scientist found out the in-vitro model by the use of Trans wells to mimic air-liquid interface of lung barrier tissues. Now-adays 2-layered PDMS micro-fluidic devices is used. Top chamber or upper layer is air filled whose functions is to allow gas exchange. The layer present below is vascular chamber which mimics the capillary network allows the perfusion for underlying cultured tissues. The liquidair interface is separated by porous membrane and provides site for cell seeding and growth. ${ }^{38}$ Fritsch et al showed the immortalized lung epithelial cells obtained from mouse. These cells are cultured by using polystyrene micro carrier beads as surface and then injected into parenchymal chamber (top chamber) for even distribution of cells. ${ }^{39}$ Blume et al used same design to study the inflammatory reactions of primary bronchial epithelial cells to pollen dust particles. The results were clear and were prior not possible with the help of static cultures. Thus, chip device showed a higher sensitivity to environmental factors. ${ }^{40}$

\section{Kidneys-on-chips}

Drug metabolism and elimination are two most important functions of kidney. Kidney cells filters the drug and other substances circulating in body. Often filtration of drug by kidney leads to nephrotoxicity which is frequent problem in drug safety evaluation. Therefore, studying the renal barriers is needed for drug development so that the resistance time in blood can be increased and safe removal of compounds after effect is done. Epithelial cell layer of kidney is involved in more reabsorption of water, salt, sugars, and proteins. As the eliminated compounds moved from urine precursor, any drugs which are not excreted properly or left behind causes unexpected toxic effects. ${ }^{41,42}$

Renal toxicity is one of the frequently reported in drug evaluation parameters and often lately diagnosed in clinical trials. Experiments on Madin-Darley Canine Kidney (MDCK) cells, proximal, distal tubule cells showed that shear stress played vital role in renal barrier functions through protein analysis and gene analysis. 
In the fluidic medium, wherein cells are grown, they showed an increase in regulation of sodium, calcium, phosphate homeostasis as well as genes involved in $\mathrm{H}^{+}$ transport, $\mathrm{pH}$ regulation of urine. In addition to these, MDCK cells also shown an increase regulation in phaseIandII enzymes, genes involved in multi-drug resistance as well as phase-III transporters. Thus, they represent in-vivo kidney cells. ${ }^{43}$

\section{Tissue cultures}

Tissue cultures includes in-vitro cultivations of tissue, cells, organs, embryos. They are mainly primary cell cultures isolated from animal tissues directly by using proteolytic enzymes. These cultures have tissue specific functions and have capacity for biotransformation. The only drawback is, cellular isolation can result in damage to cell membrane, loss of or damage to cellular contents and membrane receptors. When the cultures are kept for long time, unfavorable changes occur within cultures which causes isolation or removal new cells for each new experiment. These issues get solved by the use of "cell lines". However, as time passes by, over many years, these cell lines results in reducing metabolic capacity and altered cellular function. ${ }^{44}$ Immortalized cell lines have capacity of extending and often indefinite period of time in-vitro. They are prepared by adding viral oncogenes such as SV40, large T, EIA into primary cells along with calcium phosphate treatment. The cells that have been immortalized are rabbit kidney cells, rat hepatocytes, osteoblasts. ${ }^{45,46}$ The technique of immortalization usually changes the structure and functions. Stem cells lines are available from mammalian blastocysts and from adult progenitor cells. Stem cells are retained in their undifferentiated state in presence of feeder and Leukotriene Inhibitory Factor (LIF). Once the LIF gets removed, stem cells divide into various other cells types. Therefore, making stem cells their characteristic name "pluripotent cells" or "multi potent cells" when taken from adult organs. Stem cells derived from human embryos now raise considerable ethical and sociological questions. The major difference in stem cells and immortalized cells is that stem cells have ability of selfrenewal capacity which immortalized cells lack. Hence, for this reason, stem cells are preferred more than immortalized cells. ${ }^{47,48}$ Research centers uses stem cells for their major use to compensate the lost tissue and functional cells in the cases of degenerative diseases. In some cases, stem cells also contribute in blood cell production (haemopoiesis) and several haemotopoeitic cytokines and recently used in cancer treatment along with chemotherapy and radiation therapy. ${ }^{49}$

\section{In-vitro assays}

In order to check the toxicity of eye corrosion, skin corrosion, carcinogenicity, in-vitro assays are employed which involves bacterial, yeast, human cell cultures, mammalian cell. The advantage is that some have been scientifically validated whereas the remaining are on the way to rapid development..$^{50}$

\section{Perfused cultures}

Mainly two types of tissue culture are performed: static or perfused along with culture media via pumps. When the cells are exposed to toxins, perfusion cultures show the accurate monitoring of cytotoxins. Cytotoxins are identified and detected with the help of biomarkers present in the perfusion. The advantage is that perfusion culture's shows important parameters like onset of toxic action, toxicity scale, duration time of toxic action can be measured which were previously difficult in static cultures or in-vivo analysis. ${ }^{51}$

\section{Human hepatocytes}

Liver is the major organ used for metabolism and distribution of drugs in systemic circulation. Liver receives bolus of concentrated ingested drug delivered from intestine through portal circulation. Thus, liver cells are the first to react and respond to the ingested foreign substance. Enzymes present such as P450 dependent mono-oxygenase responsible for metabolism. Liver cells can be studied in-vitro by the use of human hepatocytes cultures. They are commonly used for drug- drug interaction, drug potential and drug toxicity in both academics as well as research labs. With the development of crypto-preservation, with the use of reagents and protocols leads to protection to membranes from damage associated during preserving techniques. ${ }^{52}$

\section{Green-screen genotoxicity assays}

Lichtenberg- Frate and colleagues used genetically modified Saccharomyces cerevisiae along with green fluorescent protein fused to RAD54 yeast promoter n DNA damage, green fluorescent gets emitted and it indicated several genotoxic test compounds. This phenomenon is called "green-screen genotoxicity assays". This technique is employed for checking the number of genotoxins and non-genotoxins with very high level of accuracy as per study performed on 75 chemicals. ${ }^{53}$

\section{CONCLUSION}

Every religious book focuses on the principle "Live and Let Live". This line is not merely applicable to humans but also to animals. Just as we humans have right against slavery and cruelty, so with the animals. Many legal 
aids are available to animals such as the act formed in 1824 by Royal Society of Prevention of Animal Right. In order to bypass these animal safety laws, there came the need to develop non-animal models. Some of these techniques such as in-silico methods, minimally sentient method, in-vitro assays and microfluidic techniques are focused in this article. By the rational use of these methods, the use of animals can be significantly minimized and the principle "Live and Let Live" can be fulfilled.

\section{ACKNOWLEDGMENT}

The authors acknowledge School of Pharmacy and Technology Management, SVKM's NMIMS, Shirpur campus, Maharashtra, India for assistance.

\section{CONFLICT OF INTEREST}

None

\section{REFERENCES}

1. Hackam DG, Redelmeier DA. Translation of research evidence from animals to humans. JAMA. 2006;296(14):1731-32.

2. Giacomotto J, Segalat L. High-throughput screening and small animal models, where are we? Br. J. Pharmacol. 2010;160(2):204-16.

3. Washington USA: National Academies Press. Science, Medicine and Animals; a report from Institute for Laboratory Animal Research. 2004;1-2.

4. Pearce AI, Richards RG, Milz S, Schneider E, Pearce SG. Animal models for implant biomaterial research in bone: A review. Eur Cell Mater. 2007;13(1):1-10.

5. Theodora Hatziioannou and David T. Evans Animal models for HIVIAIDS research Nature Reviews Microbiology. 2012;10:(12):852-67.

6. Balls M. Replacement of animal procedures: alternatives in research, education and testing. Lab. Anim.1994;28(3):193-211.

7. Ranganatha N, Kuppast I.J. A review on alternatives to animal testing methods in drug development. Int. J. Pharm. Pharm. Sci. 2012;4(Suppl 5):28-32.

8. Banks RE. The 4th R of Research. Contemp Top Lab Anim Sci.1995;34:43.

9. Kimber I, Pichowski JS, Betts CJ, Cumberbatch M, Basketter DA, Dearman RJ. Alternative approaches to the identification and characterization of chemical allergens. Toxicol. In vitro. 2001; 15(4):307-12.

10. Gipson I, Sugrue S. Cell biology of the corneal epithelium. In: Albert D, Jakobiec F. (Eds.) Principles and Practice of Ophthalmology. Saunders WB. 1994:4-16.

11. Hendriksen CF. Replacement, reduction and refinement alternatives to animal use in vaccine potency measurement. Expert Rev. Vaccines. 2009;8(3):313-22.

12. Schechtman LM. Implementation of the $3 R$ s (refinement, reduction, and replacement): Validation and regulatory acceptance considerations for alternative toxicological test methods. ILAR J. 2002;43(Suppl 1):85-94.

13. Kapetanovic IM. Computer-Aided Drug Discovery and Development (Caddd): in silico-chemico-biological approach Chem Biol Interact. 2008;171(2):165-76.

14. Li Hongyu, et al. "Cytotoxicity, qualitative structure-activity relationship (QSAR), and anti-tumor activity of bismuth dithiocarbamate complexes." Journal of inorganic biochemistry. 2007;101(5):809-16.

15. Cosson et al. Pseudomonas aeruginosa virulence genes identified in a Dictyostelium host model Journal of Bacteriology. 2002;184(1):3027-33.

16. Kari G, Rodeck $U$ and Dicker AP. Zebrafish: An Emerging Model System for Human Disease and Drug Discovery. Clinical Pharmacology and Therapeutics. 2007;82(1):70-80.

17. Hill AJ, Teraoka H, Heideman W, Peterson RE. Zebra fish as a model vertebrate for investigating chemical toxicity. Toxicol. Sci. 2005;86(1):6-19.
18. Wilson-Sanders SE. Invertebrate models for biomedical research, testing, and education. ILAR J. 2011;52(2):126-52.

19. Pandey UB, Nichols CD. Human disease models in Drosophila melanogaster and the role of the fly in therapeutic drug discovery. Pharmacol. Rev. 2011;63(2):411-36.

20. lijima K, Liu HP, Chiang AS, Hearn SA, Konsolaki M, Zhong Y. Dissecting the pathological effects of human Abeta40 and Abeta42 in Drosophila: a potential model for Alzheimer's disease. Proc. Natl. Acad. Sci. 2004;101(17):6623-8.

21. Bonini NM, Fortini ME. Human neurodegenerative disease modeling using Drosophila. Ann. Rev. Neurosci. 2003;26(1):627-56.

22. Artal-Sanz M, de Jong L, Tavernarakis N. Caenorhabditis elegans: a versatile platform for drug discovery. Biotech J. 2006;1(12):1405-8.

23. Nass R, Merchant KM, Ryan T. Caenorhabditis elegans in Parkinson's disease drug discovery: addressing an unmet medical need. Mol. Intervention. 2008;8(6):284-93.

24. Pujol N, Cypowyj S, Ziegler K, Millet A, Astrain A, Goncharov A, et al. Distinct innate immune responses to infection and wounding in the $C$. elegans epidermis. Curr. Biol. 2008;18(7):481-9.

25. Link CD, Johnson CJ, Fonte V, Paupard M, Hall DH, Styren S, et al. Visualization of fibrillary amyloid deposits in living, transgenic Caenorhabditis elegans animals using the sensitive amyloid dye, X-34. Neurobiol. Aging. 2001;22(2):217-26.

26. Mell JC, Burgess SM. Yeast as a model genetic organism. Encyclopedia of Life Sciences. Mcmillan Publishers Ltd. 2002;1-8.

27. Madeo F, Engelhardt S, Herker E, Lehmann N, Maldener C, Proksch A, et al. Apoptosis in yeast: a new model system with applications in cell biology and medicine. Curr. Genet. 2002;41(4):208-16.

28. Pereira C, Bessa C, Soares J, Leao M, Saraiva L, 2012. Contribution of yeast models to neurodegeneration research. J. Biomed. Biotech. 2012;1-12.

29. Siggers KA, Lesser CF. The yeast Saccharomyces cerevisiae: a versatile model system for the identification and characterization of bacterial virulence proteins. Cell Host Microbe. 2008;4(1): 8-15

30. Williams $\mathrm{CH}$, Hong $\mathrm{CC}$. Multi-step usage of in vivo models during rational drug design and discovery. Int. J. Mol. Sci. 2011;12(4):2262-74.

31. Chung S, Sudo R, Mack PJ, Wan CR, Vickerman V, Kamm RD. Cell migration into scaffolds under co-culture conditions in a microfluidic platform. Lab Chip. 2009;9(2):269-75.

32. Huh D, Matthews BD, Mammoto A, Montoya- Zavala M, Hsin HY, Ingber DE. Reconstituting organ-level lung functions on a chip. Science. 2010;328(5986):1662-8.

33. Pasparakis M, Haase I, Nestle FO. Mechanisms regulating skin immunity and inflammation. Nat. Rev. Immunol. 2014;14(5):289-301.

34. An F, Qu Y, Liu X, Zhong R, Luo Y. Organ-on-a-chip: New Platform for Biological Analysis. Anal Chem Insights. 2015;10:39-45.

35. Moraes C, Mehta G, Lesher-Perez CS, Takayama S. Organ- on-a- chip: Focus on Compartmentalized microdevices. Ann Biomed Eng. 2012;40(6):1211-27.

36. Sakolish CM, Esch MB, Hickman JJ, Shuler ML, Mahler GJ. Modeling Barrier Tissues In vitro: Methods, Achievements, and Challenges. E Bio Medicine. 2016;5:30-9.

37. Davila JC, Rodriguez RJ, Melchert RB, Acosta Jr D. Annu. Rev. Pharmacol. Toxicol. 1998;38(1):63-96.

38. Huh D, Matthews BD, Mammoto A, Montoya-Zavala M, Hsin HY, Ingber DE. Reconstituting Organ-Level Lung Functions on a Chip Science. 2010;25: 328(5986):1662-8.

39. Fritsche CS, Simsch O, Weinberg EJ, Orrick B , Stamm C, KaazempurMofrad MR, et al. Pulmonary tissue engineering using dual-compartment polymer scaffolds with integrated vascular tree. The International Journal of Artificial Organs. 2009;32(10):701-10.

40. Blume C, Davies DE. In vitro and ex vivo models of human asthma. European Journal of Pharmaceutics and Biopharmaceutics. 2013;84(2):394-400.

41. Kim, S. et al. Pharmacokinetic profile that reduces nephrotoxicity of gentamicin in a perfused kidney-on-a-chip. Biofabrication. 2016;8(1):015021.

42. Sung $\mathrm{JH}, \mathrm{Kam} \mathrm{C}$. Shuler ML. A microfluidic device for a pharmacokineticpharmacodynamic (PK-PD) model on a chip. Lab Chip. 2010;10(4):446-55.

43. Chang SY, Weber EJ, Van NKP, Eaton DL, Kelly EJ. Liver and kidney on chips: microphysiological models to understand transporter function. Clinical Pharmacology and Therapeutics. 2016;100(5):464-78. 
44. Shay JW, Wright WE. The use of telomerized cells for tissue engineering. Nat. Biotech. 2000;18(1):22-3.

45. Ramboer E, Vanhaecke T, Rogiers V, Vinken M. Immortalized human hepatic cell lines for in vitro testing and research purposes. Methods Mol Biol. 2015;1250:53-76.

46. Kang SS, Wang L, Kao WW, Reinach PS, Lu L. Control of SV-40 transformed RCE cell proliferation by growth-factor-induced cell cycle progression Curr Eye Res. 2001; 23(6): 397-405.

47. Bhangra KS, Busuttil F, Phillips JB, Rahim AA. Using Stem Cells to Grow Artificial Tissue for Peripheral Nerve Repair Stem Cells Int. 2016;2016:7502178.

48. Wobus AM, Löser P. Present state and future perspectives of using pluripotent stem cells in toxicology research. Arch Toxicol. 2011;85(2):79-117.
49. Lin HT, Otsu M, Nakauchi H. Stem cell therapy: an exercise in patience and prudence. Philos Trans R Soc Lond B Biol Sci. 2013;368(1609):20110334.

50. Khademhosseini A1, Langer R, Borenstein J, Vacanti JP. Microscale technologies for tissue engineering and biology. Proc Natl Acad Sci. 2006;103(8):2480-7.

51. Griffith LG1, Swartz MA. Capturing complex 3D tissue physiology in vitro. Nat Rev Mol Cell Biol. 2006; 7(3): 211-24.

52. Li AP. In vitro human hepatocyte-based experimental systems for the evaluation of human drug metabolism, drug-drug interactions, and drug toxicity in drug development. Curr Top Med Chem. 2014;14(11):1325-38.

53. Alkyuz N, Weismuller L. Proof of principle: detection of genotoxicity by a fluorescence-based-recombination test in mammalian cells. Altex. 2003;20(2):77-84.

\section{PICTORIAL ABSTRACT}

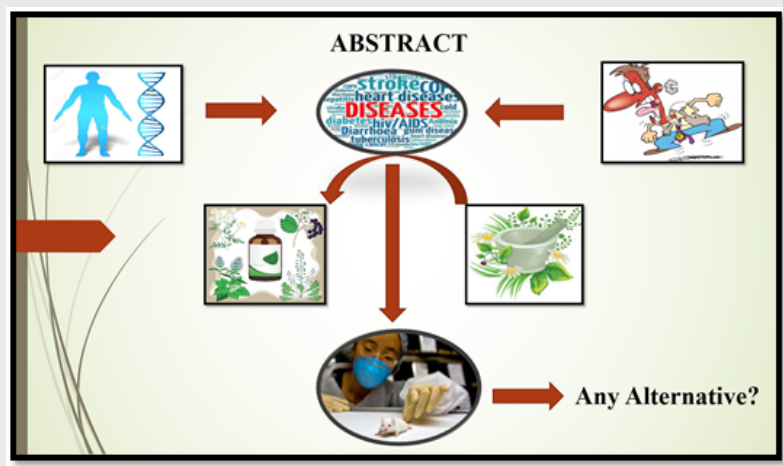

\section{About Authors}

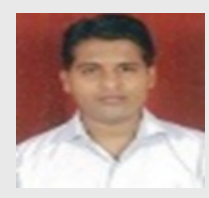

Mr. Parshuram Shendge: Is working as a lecturer in School of Pharmacy \& Technology Management, SVKM's NMIMS, Shirpur campus, Dhule, Maharashtra, India. He completed his Master of Pharmacy (Pharmacology) from Bharati Vidyapeeth's College of Pharmacy, Navi Mumbai, Maharashtra, India. His area of interest is oxidative stress, herbal drugs, metabolic syndrome \& toxicological studies.

\section{SUMMARY}

- Plant life is oldest life on Earth. They witnessed the change in nature by observing human civilization, animal growth. Early man began searching food and water from nature. Along with the time he came across, the curative properties or medicinal uses of plants.

- In research animals are being used to check the purity, standardization, safety and toxic levels of drugs. With the increase in medicinal research and development, the number of animals used in research have also been increasing. Each year around 2-3 million animals are used for experimental research. For a long time, animals such as rabbits, mice, hamsters, birds, guinea pigs, and many more are used.

- Different methods have been developed to replace animals during drug testing in research and toxicology study. The methods we have discussed here are: In silico methods, minimally sentient, organ on chips, etc.

Mr. Abhishek Ajmera: Is currently studying at School of Pharmacy \& Technology Management, SVKM's NMIMS, Shirpur campus, Dhule, Maharashtra, India. His area of interest is new scientific techniques for pharmacological research, drug development \& stability studies.

Cite this article: Ajmera A, Shendge P. Non-Animal Models for Research and Toxicity Testing of Drugs. Indian J of Pharmaceutical Education and Research. 2017;51(4S):S531-S8. 